\title{
Retraction
}

\section{Reevaluation of the documentation of the technique used for the work "Combined use of confocal laser scanning microscopy and transmission electron microscopy for visualization of identical cells processed by cryotechniques"}

\author{
Roger Wepf ${ }^{1}$, Marita Beese ${ }^{2}$, Karin Krupinska ${ }^{3}$ \\ ${ }^{1}$ Electron Microscopy ETH Zurich, Swiss Federal Institute of Technology Zurich, Zurich \\ ${ }^{2}$ Center of Microscopy, Center of Biology, University of Kiel, Kiel \\ ${ }^{3}$ Institute of Botany, University of Kiel, Kiel
}

Published online 30 April 2008

(c) Springer-Verlag 2008

A method allowing to analyse cells by transmission electron microscopy (TEM) which had been preselected by confocal microscopy (CLSM) would be of great advantage for cell biological studies, since it would help to bridge the gap between CLSM and TEM. This is in particular relevant for studies of complex tissues such as leaves. Serial sectioning for TEM is extremely time-consuming, and taking semithin sections for light microscopic screening is destructive. It is nearly impossible to re-embed a semithin section for TEM.

In an article by Pfeiffer et al. (2003), it has been claimed that defined cells of plant tissue which were depicted in optical sections by CLSM can be identified and analysed by TEM. This statement is supported exclusively by the images shown in Fig. 3 of the article (Figs. 1 and 2 of this reevaluation).

Since the TEM micrograph in Fig. $3 c$ of the article shows only a very small area of the tissue, it is difficult to compare it with the optical section in Fig. 3b. Furthermore, the tissues shown on the micrographs are oriented in different directions. Figure $3 \mathrm{c}$ is a selected area of a larger TEM overview image (Fig. 1) which had been presented on a poster (Pfeiffer et al. 2001). It shows a section of vascular tissue (phloem). The tissue shown in the overview TEM image, however, differs from the tissue shown in Fig. 3 b of the article. Evidence that the CLSM

Correspondence: Karin Krupinska, Botanisches Institut und Botanischer Garten, Christian-Albrechts-Universität zu Kiel, Olshausenstrasse 40, 24098 Kiel, Federal Republic of Germany.

E-mail: kkrupinska@bot.uni-kiel.de and TEM micrographs in the article do not show the same cells is presented below.

Image analysis by SIFT features (Kaynig et al. 2007) revealed that the correlation of the selected cells labelled by a red line is high between the TEM image of the article and the overview TEM image of the poster (Fig. 1). The images can be aligned with a precision of 1.5 pixel based on the corresponding points automatically obtained by SIFT features. Figure $3 \mathrm{c}$ of the article, which corresponds to the sector presented at the right side of Fig. 1, thus shows clearly a selected area of the overview TEM micrograph of the poster (Fig. 1).

When the CLSM image of Fig. $3 \mathrm{~b}$ of the article and the TEM overview image are superimposed (Fig. 2), severe mismatches of cellular structures are detectable. No correspondence of the cells in the environment of the marked cells was found between the CLSM image and the electron micrograph (Fig. 2). The number of cells between those labelled by a red line and the edge of the section is lower in the CLSM image than in the TEM image. Despite the different orientation of the selected TEM image, the lack of correspondence in the cellular structures surrounding the cells labelled by a red line between TEM and CLSM images is also detectable in Fig. 3 of the article by Pfeiffer et al. (2003). Because the original images are not available anymore, a more detailed image analysis by SIFT features is not possible.

The article by Pfeiffer et al. (2003) claimed that "a newly constructed specimen holder enabled precise relocation of the target cells for microscopic investigations". 

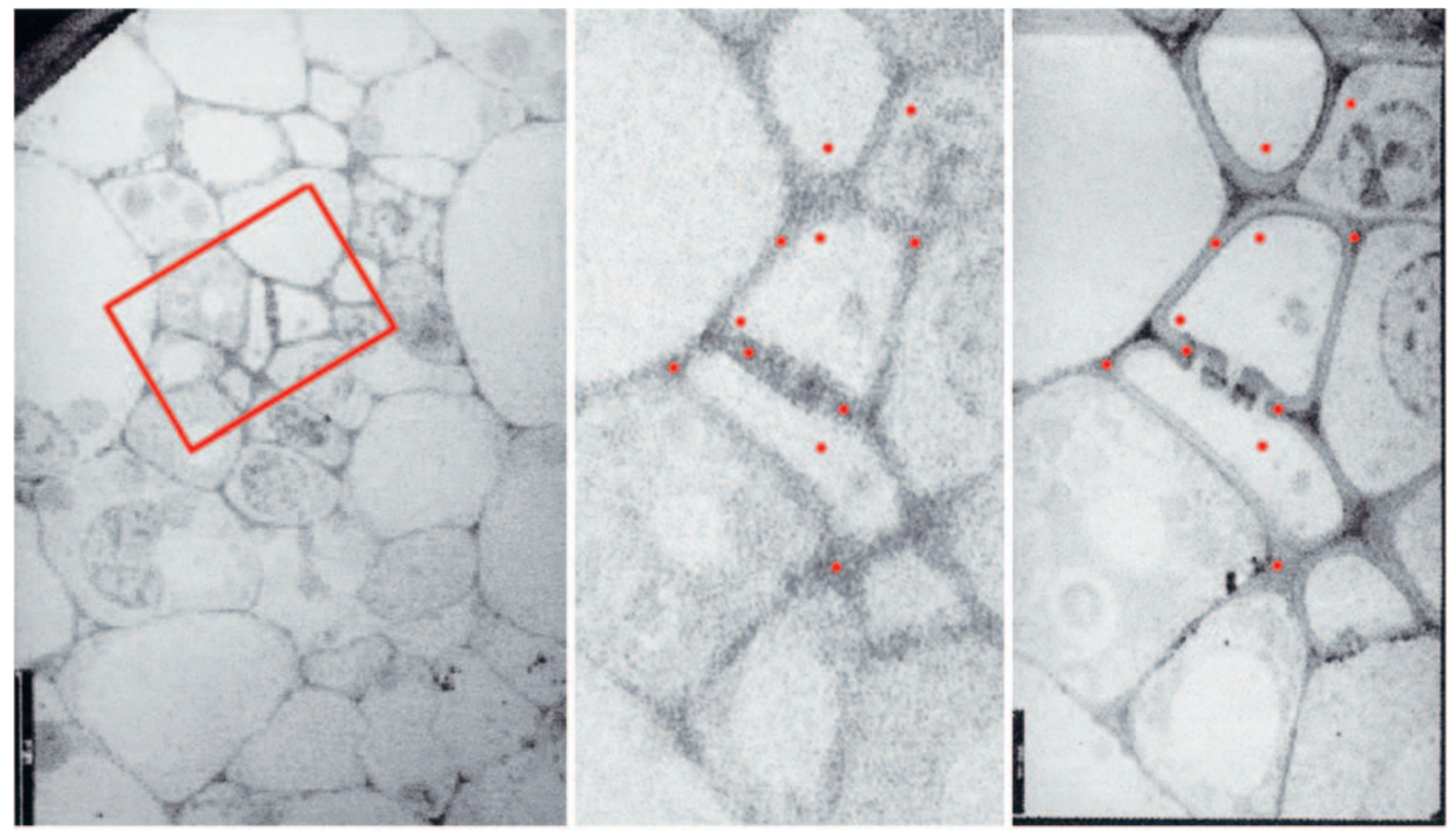

Fig. 1. TEM images of vascular tissue. On the left a TEM overview image originally presented on a poster (Pfeiffer et al. 2001) is shown. The sector in the red frame is turned and compared to the TEM image corresponding to Fig. 3c of Pfeiffer et al. (2003), which here is shown at the right side. Red dots facilitate the comparison between the two selected area TEM images
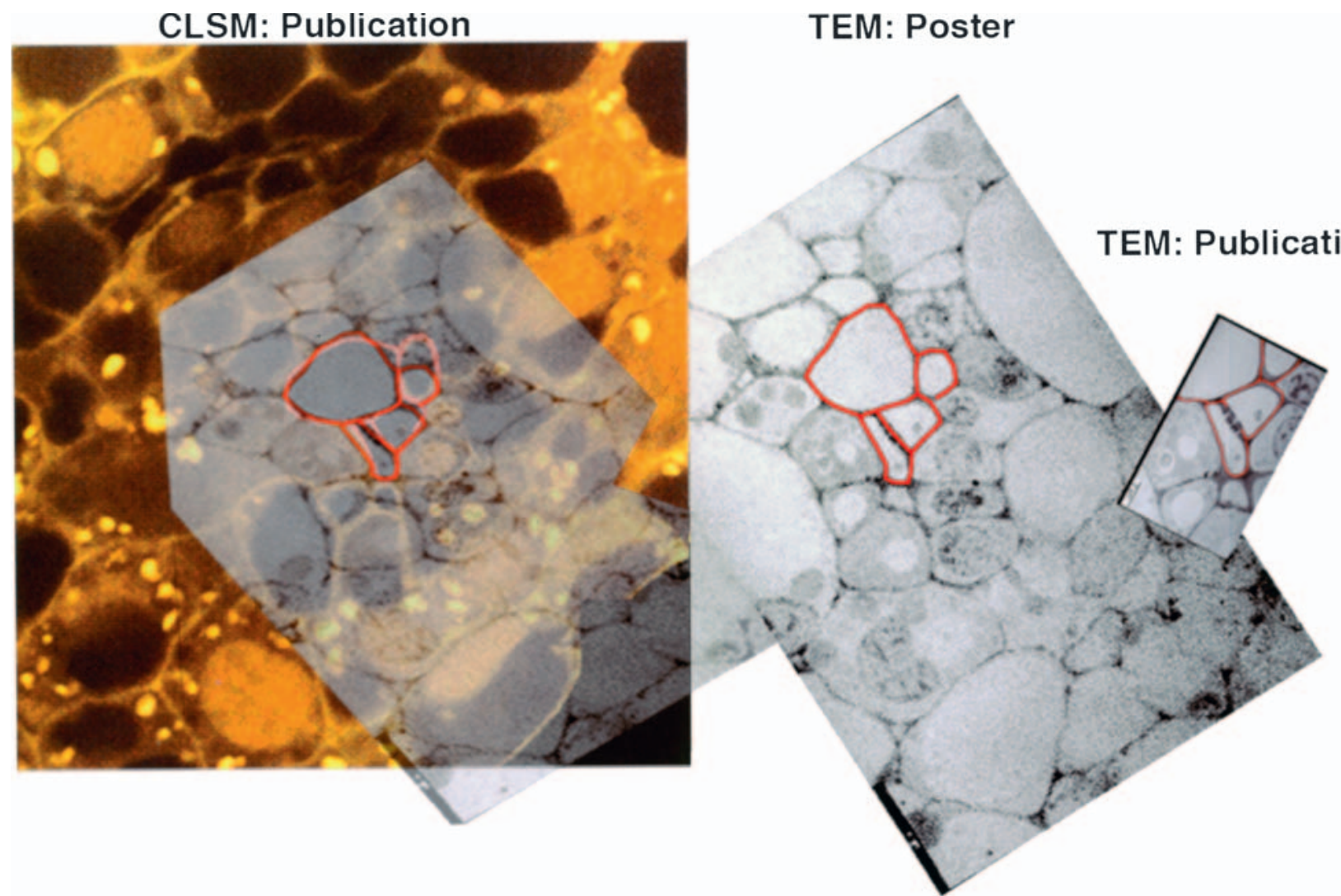

Fig. 2. Overlay of the CLSM optical section shown in Fig. 3b of Pfeiffer et al. (2003) and the TEM images presented in Fig. 1 
The same embedded cells first visualized by their fluorescence were reported to be reimaged by TEM subsequently. Our data, however, show that the fluorescence and the TEM image clearly do not show the same cells. Within the depth resolution of CLSM (500-1000 nm) structural changes at this magnitude are not possible between consecutive ultrathin sections $(70-100 \mathrm{~nm})$ for TEM in the CLSM probed volume.

The senior author deeply regrets any scientific expectations that have resulted from the publication of this procedure. Nevertheless, it is basically possible to correlate light and electron microscopy. Prerequisite is the use of internal references (Biel et al. 2003).

\section{References}

Biel SS, Kawaschinski K, Wittern K-P, Hintze U (2003) From tissue to cellular ultrastructure: closing the gap between micro- and nanostructural imaging. J Microsc 212: 91-99

Kaynig V, Fischer B, Wepf R, Buhmann JM (2007) Fully automatic registration of electron microscopy images with high and low resolution. Microsc Microanal 13 (Suppl 2): 198-199

Pfeiffer S, Dähnhardt D, Beese M, Krupinska K (2001) The combination of the confocal laser scanning microscopy (CLSM) technique and transmission electron microscopy (TEM) simplifies the visualization of the same cells in CLSM and TEM, on the basis of only one preparation technique. Biol Cell 93: 242

Pfeiffer S, Beese M, Boettcher M, Kawaschinski K, Krupinska K (2003) Combined use of confocal laser scanning microscopy and transmission electron microscopy for visualization of identical cells processed by cryotechniques. Protoplasma 222: 129-137

Verleger: Springer-Verlag GmbH, Sachsenplatz 4-6, 1201 Wien, Österreich. - Herausgeber: Dr. P. Nick, Institut für Biologie, Universität Karlsruhe, Kaiserstraße 2, 76128 Karlsruhe, Bundesrepublik Deutschland. - Redaktion: Sachsenplatz 4-6, 1201 Wien, Österreich. - Satz und Umbruch: Thomson Press (India) Ltd., Chennai. - Druck: Holzhausen Druck und Medien GmbH, Holzhausenplatz 1, 1140 Wien, Österreich. - Verlagsort: Wien. - Herstellungsort: Wien. - Printed in Austria Offenlegung gem. § 25 Abs. 1 bis 3 Mediengesetz. 